\title{
PEMBERDAYAAN KESEHATAN MELALUI PENYULUHAN YANG BERTEMA PENYAKIT TUBERCULOSIS PADA ANAK USIA DINI
}

\author{
Denai Wahyuni*, Henny Maria Ulfa, Yeyen Gumayesty, Firman Edigan \\ Sekolah Tinggi Ilmu Kesehatan Hang Tuah Pekanbaru \\ email: hennyulfa84@gmail.com
}

\begin{abstract}
Age of child is a very prone age to the transmission of the disease tubercolosis. The rate of transmission and danger of high transmission is in the age of 0-6 years and the age of 7-14 years. The age of children is very prone to contracting tubercolosis when infected they are easily affected by the disease tubercolosis. Consciousness, the participation of students is needed prevention efforts, eradication of Tubercolosis disease. There are still many early childhood children understanding of the disease Tubercolosis, the devotion of the knowledge of early childhood to better understand, applying that the importance of prevention of the disease tubercolosis. To the mother and father of teachers, to provide supervision and education to students in the school
\end{abstract}

Keywords: Tuberculosis, disease, interception

\section{Abstrak}

Usia anak merupakan usia yang sangat rawan terhadap penularan penyakit tubercolosis. Angka penularan dan bahaya penularan yang tinggi terdapat pada golongan umur 0-6 tahun dan golongan umur 7-14 tahun. Usia anak sangat rawan tertular tubercolosis apabila terinfeksi mereka mudah terkena penyakit tubercolosis. Kesadaran, partisipasi siswa-siswi sangat dibutuhkan upaya pencegahan, pemberantasan penyakit Tubercolosis. Masih banyak anak-anak usia dini kurang pemahaman terhadap penyakit Tubercolosis, adanya pengabdian ini pengetahuan anak usia dini agar lebih memahami, menerapkan bahwa pentingnya pencegahan penyakit tubercolosis.Kepada ibu dan bapak guru, agar lebih memberikan pengawasan serta edukasi kepada siswa-siswi di sekolah

Kata Kunci: Tuberculosis, penyakit, pencegaan

\section{PENDAHULUAN}

Di Indonesia, TB merupakan masalah utama kesehatan. Jumlah pasien TB di Indonesia merupakan ke-3 terbanyak di dunia setelah India dan Cina. Diperkirakan pada tahun 2004, setiap tahun ada 539.000 kasus baru dan kematian 101.000 orang (Anonim, 2007). Di Indonesia dengan prevalensi TB positif 0,22\% (laporan WHO, 1998), penyakit ini merupakan salah satu penyakit yang setiap tahun mortalitasnya cukup tinggi. Kawasan Indonesia timur banyak ditemukan terutama gizi makanannya tidak memadai dan hidup dalam keadaan sosial ekonomi dan higiene dibawah normal (Tjay dan Rahardja, 2007).
Pada anak, TB secara umum dikenal dengan istilah "flek paru-paru". Tubercolosis pada anak juga mempunyai permasalahan khusus yang berbeda dengan orang dewasa, baik dalam aspek diagnosis, pengobatan, pencegahan, maupun TB paada kasus khusus, misalnya pada anak dengan infeksi HIV (Anonim, 2011). Perbedaan TB anak dengan TB dewasa adalah TB anak lokasinya pada setiap bagian paru sedangkan pada dewasa didaerah apeks dan infra klavikuler. Kemudian terjadi pembesaran kelenjar limfe regional sedangkan pada dewasa tanpa pembesaran kelenjar limfe regional. Pada anak penyembuhan dengan perkapuran dan pada dewasa dengan fibrosis. Pada anak lebih banyak terjadi 
penyebaran hematogen sedangkan pada dewasa jarang (Sulaifi, 2011).

Usia anak merupakan usia yang sangat rawan terhadap penularan penyakit tubercolosis. Angka penularan dan bahaya penularan yang tinggi terdapat pada golongan umur 0-6 tahun dan golongan umur 7-14 tahun. Usia anak sangat rawan tertular tubercolosis dan apabila terinfeksi mereka mudah terkena penyakit tubercolosis.

Kesadaran dan partisipasi siswa-siswi sangat dibutuhkan dalam upaya pencegahan dan pemberantasan penyakit Tubercolosis. Dengan adanya kegiatan penyuluhan diharapkan siswa-siswi mengerti dan memahami apa itu penyakit tubercolosis, penyebab penyakit dan bagaimana penularan penyakit tubercolosis, serta bagaimana usaha untuk pencegahan dan pemberantasan penyakit tubercolosis. Salah satu daerah di wilayah kota Pekanbaru yaitu tepatnya di Kulim yang tempat penduduknya cukup padat dan ramai, dan daerah ini yang sangat rawan akan penyakit tubercolosis karena tempatnya yang lembab dan sering terkena banjir.

Dari hasil survei yang dilakukan oleh kelompok, ternyata terdapat salah satu sekolah dasar yang terletak di Kulim yaitu SD Negeri 171 Tenayan Raya, yang letaknya cukup jauh dari jalan besar dan keadaan siswa-siswi nya dan lingkungan yang kurang nyaman pada sekolah tersebut. Berdasarkan latar belakang diatas, kelompok tertarik untuk melakukan penyuluhan tentang "Penyakit Tubercolosis pada Anak Usia Dini”.

\section{METODE PENGABDIAN}

Salah satu daerah di wilayah kota Pekanbaru yaitu tepatnya di Kulim terdapat sekolah dasar yang menjadi sasaran penyuluhan kelompok yaitu SD. Sebelum melakukan penyuluhan kelompok melakukan identifikasi terhadap sekolah tersebut terdapat faktor lingkungan yang kurang baik bagi siswa-siswi yang merupakan tempat menyebarnya bakteri penyakit Tubercolosis.

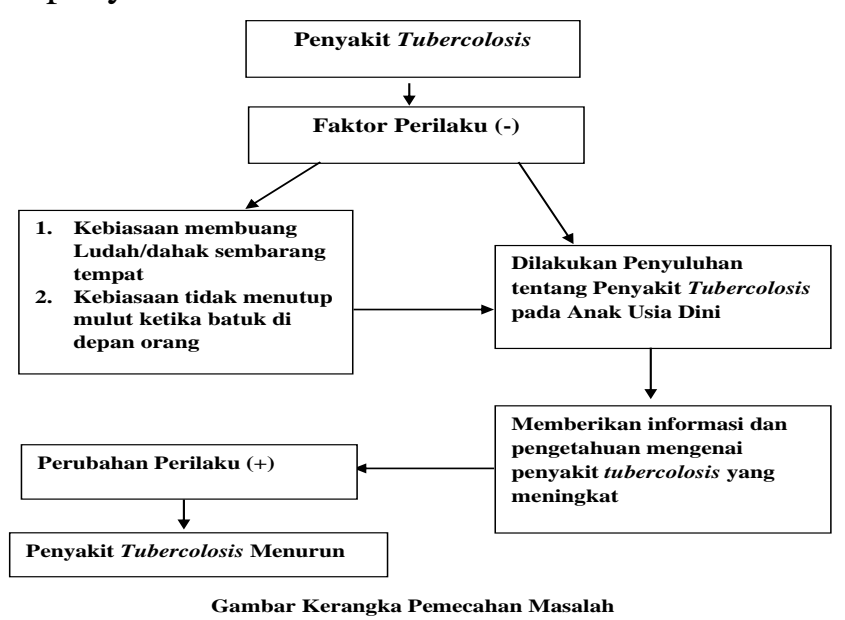

Khalayak Sasaran Antara Yang Strategis

Sasaran dalam kegiatan penyuluhan ini adalah siswa-siswi

\section{Keterkaitan}

Kegiatan penyuluhan ini dilakukan oleh STIKes HangTuah Pekanbaru dengan siswa-siswi di SD SD Negeri 171 Tenayan Raya

\section{Rancangan Evaluasi}

1. Input/Proses

a) Menciptakan rasa ingin tahu pada siswasiswi SD tentang Penyakit Tubercolosis pada Anak Usia Dini.

b) Melihat kembali perkembangan siswasiswi, peserta penyuluhan dalam memahami materi tentang Penyakit Tubercolosis pada Anak Usia Dini.

2. Output/Hasil

a) Hasil yang diharapkan dari penyuluhan tersebut agar siswa-siswi dapat menerapkan pencegahan tentang penyakit dengan baik.

b) Guru juga harus mengawasi dan mengurusi siswa-siswinya yang berada di SD

\section{Metode Kegiatan}

1. Memberikan pre test

2. Memberikan arahan kepada siswasiswi yang mengikuti penyuluhan tentang Penyakit Tubercolosis pada Anak Usia Dini. 
3. Meyampaikan materi tentang Penyakit Tubercolosis pada Anak Usia Dini.

4. Memberikan post test

5. Memberikan doorprize pada siswasiswi yang dapat menjawab pertanyaan.

\section{Pelaksanaan Kegiatan}

1. Sasaran Kegiatan

Sasaran kegiatanpengabdian masyarakat ini adalah siswa dan siswi di SD SD Negeri 171 Tenayan Raya

\section{Tempat dan Waktu Kegiatan}

Tempat Pelaksanaan Kegiatan Pengabdian ini adalah di SD SD Negeri 171 Tenayan Raya

\section{Metode}

Metode yang digunakan dalam kegiatan pengabdian ini adalah menerangkan dan memberikan contoh cara mencegah yang benar sesuai anjuran DepKes RI, ceramah, tanya jawab dan memberikan snacks makanan dalam kegiatan penyuluhan berlangsung. Kemudian dilakukan evaluasi dengan memberikan pertanyaan untuk melihat dan menilai apakah sasaran dapat memahami materi yang diberikan oleh penyuluh atau tidak, kemudian siswa-siswi yang dapat menjawab pertanyaan diberikan doorprise agar menjalin kedekatan dan suasana yang tidak tegang.

\section{Jadwal Kegiatan}

Kegiatan pengabdian masyarakat dihadiri oleh siswa-siswi, guru-guru yang merupakan pendamping/wali kelas di SD SD Negeri 171 Tenayan Raya

\section{Hasil dan Pembahasan}

\section{Hasil}

\section{Pre-test dan Post-test}

Pre-test dan post-test yang dilakukan menggunakan tes lisan. Hasil pre-test yang dilakukan diketahui $20 \%$ siswa-siswi yang dapat menjawab pertanyaan yang diajukan terkait dengan materi yang diberikan. Setelah dilakukannya pemberian materi tentang penyakit tubercolosis pada anak usia dini, dilakukannya post-test secara lisan.
Dan didapatkan bahwa $95 \%$ dapat menjawab pertanyaan yang diberikan oleh pemateri. Hal ini menunjukkan bahwa adanya perubahan pengetahuan yang diperoleh oleh siswa-siswi yang mengikuti kegiatan penyuluhan ini.

\section{Pembahasan}

Berdasarkan hasil pre-test dan post-test dapat dilihat adanya perbedaan hasil pengetahuan siswa-siswi. Pada saat pre-test sebagian besar siswa-siswi belum dapat menjawab pertanyaan yang diberikan oleh tim penyuluh. Hanya beberapa diantara mereka yang dapat menjawab pertanyaan. Namun, jawaban yang disampaikan dirasa masih kurang begitu tepat. Sedangkan pada saat post-test seluruh siswa-siswi dapat menjawab pertanyaan yang diberikan dengan baik dan ada juga siswa-siswi yang dapat menyimpulkan keseluruhan materi dengan baik.

Berdasarkan hasil pre-test dan post-test tersebut, dapat disimpulkan bahwa sebagian responden belum mengetahui dengan benar mengenai materi. Salah satu faktor yang mungkin dapat menyebabkannya adalah kurangnya pengetahuan. Namun setelah dilakukan penyuluhan, pengetahuan daro beberapa siswa-siswi bertambah baik, hal ini dapat dilihat dari hasil post-test yang dilakukan.

Dengan adanya penyuluhan ini, diharapkan dapat menambah pengetahuan seluruh siswa-siswi yang baik. Sehingga seluruh siswa-siswi dapat berperilaku positif dan dapat melakukan pencegahan dan pemberantasan penyakit Tubercolosis pada anak usia dini di SD Negeri 171 Tenayan Raya Pekanbaru.

\section{SIMPULAN}

Masih banyak anak-anak usia dini yang kurang banyak pemahaman terhadap penyakit Tubercolosis, dengan adanya pengabdian ini pengetahuan anak usia dini tentang penyakit Tubercolosis akan lebih meningkat dan pemahaman tentang penyakit Tubercolosis ini akan lebih baik. perlu diperhatikan adalah siswa-siswi yang 
ISSN : 2550-0198

berada di SD agar lebih memahami dan menerapkan pencegahan penyakit Tubercolosis di sekolah dan pentingnya pencegahan penyakit tubercolosis, guruguru, agar lebih memberikan pengawasan serta edukasi kepada siswa-siswi di SD SD Negeri 171 Tenayan Raya.

\section{DAFTAR PUSTAKA}

[1]. Hartoyo, E., dan Roni, N. 2002. "Tuberkulosis Milier dengan Hepatitis Tipe Kolestasis, Berkala". Ilmu Kedokteran, Vol.34, No.2, 117-118.

[2]. Icksan dan Luhur. 2008. "Radilologi Toraks Tuberkulosis Paru”. Jakarta: CV. Sagugn Seto.

[3]. Malueka, R. Ghazali. 2008. "Radiologi Diagnostik". Yogyakarta: Pustaka Cendekia.

[4]. Tjay, Tan Hoan dan Raharja Kirana. 2007. “Obat-obat Penting". Elex Media Komputindo, Jakarta.

[5]. Anonim. 2002. "Pedoman Nasional Penanggulangan Tuberkulosis". Jakarta:DepKes RI.

[6]. Anonim. 2006. "Pharmaceutical Care untuk Penyakit Tuberkulosis". Jakarta:DepKes RI.

[7]. Anonim. 2007. "Pedoman Nasional Penanggulangan Tuberkulosis Edisi II". Jakarta:DepKes RI.

[8]. Anonim. 2008. "Informatorium Obat Nasional Indonesia". Jakarta: DepKes RI.

[9]. Anonim. 2009. "Kumpulan Kuliah Farmakologi, Edisi II". Jakarta: Buku Kedokteran EGC,.

[10]. Anonim. 2011. "Sekilas Mengenai TB Anak" (http://kesehatan.compas.com, diakses 22 Desember 2018).

[11]. Anonim. 2011. "TB di Indonesia Peringkat 5 Dunia". (online), (http://www.ppti.info/index.php/co mponent/content/article/46-arsipppti/141-tbdi-indonesia-peringkat5-dunia, diakses 22 Desember 2018) 